\title{
MATERIAIS DIDÁTICOS PARA EDUCAÇÃO A DISTÂNCIA: PERCEPÇÕES DE ESTUDANTES DA UFRPE/UAEADTEC
}

\author{
RECIFE/PE MAIO/2018 \\ Ivanda Maria Martins Silva - UFRPE - martins.ivanda@gmail.com \\ Ednara Félix Nunes Calado - UFRPE - naracala@hotmail.com \\ Ana Paula Teixeira Bruno Silva - UFRPE - anapaulabruno.ead@gmail.com \\ Adalmeres Cavalcante da Mota - UFRPE - adalmeres.ead@gmail.com \\ Tipo: Relato de Experiência Inovadora (EI) \\ Categoria: Pesquisa e Avaliação \\ Setor Educacional: EDUCAÇÃO SUPERIOR
}

\begin{abstract}
RESUMO
O objetivo deste trabalho é analisar as percepções de estudantes da UFRPE/UAB sobre os materiais didáticos impressos (MDI) para Educação a Distância (EaD), considerando as características da mídia impressa e a natureza da linguagem utilizada pelos professores/autores. A revisão da literatura contemplou enfoques de diferentes autores sobre Educação a Distância (LÉVY, 1999, MOORE e KEARSLEY, 2007), materiais didáticos impressos (FRANCO, 2007, PRETI, 2009, SILVA, 2011), bem como a natureza dialógica da linguagem utilizada no MDI (BAKHTIN, 1993). A pesquisa priorizou abordagem qualitativa, com a análise de conteúdo no tratamento dos dados coletados, por meio da aplicação de questionário online com estudantes de cursos de licenciatura, sendo estes ofertados na modalidade a distância pela UFRPE/UAB. Os resultados apontam para a preferência dos discentes em relação aos materiais impressos, mesmo tendo em vista as inovações tecnológicas e o dinamismo das mídias digitais. Na visão dos discentes, os materiais didáticos impressos são aliados no apoio à aprendizagem mediada pelas tecnologias no cenário da EaD. Além disso, os estudantes comentam sobre a integração e a convergência entre diferentes mídias como fatores relevantes para garantir a oportunidade de estudantes com dificuldades de acesso à internet e aos ambientes virtuais de aprendizagem.
\end{abstract}

Palavras-chave: Materiais Didáticos; Educação a Distância; Percepções de estudantes. 


\section{Trilhas iniciais.... por que ainda pesquisar materiais didáticos impressos para EaD?}

Simulações virtuais, realidade aumentada, jogos digitais, e-books, ambientes virtuais de aprendizagem, videoaulas, audiobooks e uma infinidade de recursos apoiam os processos de ensino e aprendizagem no contexto da Educação a Distância (EaD) no Brasil. As mídias digitais ganham destaque quando se abordam a produção e a disponibilização de conteúdos para os estudantes matriculados em cursos na modalidade a distância. As ferramentas da web 2.0 e o dinamismo do ciberespaço também podem dinamizar a elaboração de conteúdos, articulando-se com a convergência digital, a multimodalidade e a hipertextualidade. Diante desse cenário de inovações tecnológicas, o leitor deste artigo pode estar se perguntando: por que ainda pesquisar materiais didáticos impressos para EaD? Nesse sentido, propomos aqui reflexões para estarmos dialogando com tal questionamento. Comecemos, pois, com a abordagem de Preti (2009), autor que expõe vários motivos para analisarmos a aceitação dos materiais didáticos impressos nos programas de EaD no Brasil. Preti (2009) cita algumas razões para ainda estarmos tratando da mídia impressa no cenário da EaD, como: 1) o fato de o livro impresso não ser uma tecnologia nova e já participar da cultura escrita dos estudantes brasileiros; 2) crescimento da indústria de material impresso, indicando que o fim do livro impresso está longe de acontecer;3) como tecnologia, o livro já faz parte de nossa formação escolar e do nosso campo profissional, revelando-se como objeto familiar para os leitores; 4) A utilização da mídia impressa tem grande aceitação nas universidades que trabalham com EaD; 5) O crescimento da indústria do livro no campo da EaD, com a produção de materiais específicos para estudantes que participam de programas nesta modalidade, o que pode refletir uma espécie de "indústria do livro para EaD".

Os motivos listados por Preti (2009) revelam a importância da mídia impressa na formação escolar do estudante brasileiro, o que certamente podemos notar quando observamos programas nacionais direcionados ao livro didático. Estamos nos referindo aqui aos programas nacionais do livro, propostos pelo Ministério da Educação (MEC), tais como: Programa Nacional do Livro Didático (PNLD), Programa Nacional do Livro Didático para a Alfabetização de Jovens e Adultos (PNLA), Programa Nacional Biblioteca da Escola (PNBE). Por meio de tais programas, o governo federal lança editais para a seleção de obras para compor o acervo das escolas de educação básica pública com obras didáticas, pedagógicas e literárias, bem como com outros materiais de apoio à prática pedagógica. Outro ponto apresentado por Preti (2009) retoma o crescimento da indústria do material impresso no Brasil. Sob esse aspecto, não é raro percebermos a expansão do mercado editorial brasileiro, com o crescente volume de 
livros comercializados. Segundo relatório do Sindicato Nacional dos Editores de Livros (SNEL), em 2017, o Brasil teve o volume de 3.429 .623 de livros vendidos, superando os números de 2016, com 3.225.600. Conforme relatório do SNEL (2017), "o segundo período analisado das vendas de livros no Brasil em 2017 apresentou crescimento, quando comparamos seus resultados aos do mesmo período no ano anterior $(6,33 \% \mathrm{em}$ faturamento e $7,85 \%$ nas vendas em volume)".

Em uma rápida pesquisa no Banco da Biblioteca Digital Brasileira de Teses e Dissertações (BDTD), disponível em <http://bdtd.ibict.br/vufind/>, inserimos o eixo temático norteador para a busca "Materiais didáticos impressos" e verificamos o seguinte resultado: 60 Teses de Doutorado e 217 Dissertações de Mestrado. Para a pesquisa relativa ao eixo norteador da busca "Materiais didáticos impressos para Educação a Distância" obtivemos os seguintes resultados: 30 Teses de Doutorado e 133 Dissertações de Mestrado. Continuando a pesquisa, quando incluímos o eixo "Avaliação do aluno sobre materiais didáticos para Educação a Distância", notamos apenas 15 dissertações de mestrado e 2 teses de doutorado defendidas. Em síntese, parece que ainda há lacunas nas pesquisas direcionadas a estudos sobre materiais didáticos para Educação a Distância, principalmente quando o foco é o olhar do estudante no processo de avaliação dos materiais produzidos pelas diferentes instituições que trabalham com EaD.

\section{Materiais didáticos impressos para EaD.... ainda refletindo}

A Educação a Distância $(\mathrm{EaD})$ vem se destacando no cenário brasileiro, como modalidade educacional caracterizada pelas mediações entre educadores e educandos, os quais estão separados espacial e/ou temporalmente, porém unidos, conectados, interligados pelos recursos tecnológicos. (MORAN, 2002; LITTO, 2010; MOORE E KEARSLEY, 2007). No contexto da Educação a Distância (EaD) brasileira, os materiais didáticos impressos assumem papel de destaque nos processos de ensino e aprendizagem mediados pelas tecnologias. Em meio impresso, os materiais didáticos são organizados em livros, fascículos, apostilas, guias, roteiros de estudos, cadernos de aprendizagem, manuais, livros de bolso, enfim, o texto impresso poderá assumir diversas formas e formatos, visando apoiar a aprendizagem dos alunos/leitores.

$\mathrm{Na} \mathrm{EaD,} \mathrm{as} \mathrm{relações} \mathrm{entre} \mathrm{docentes} \mathrm{e} \mathrm{discentes} \mathrm{são} \mathrm{efetivadas} \mathrm{por} \mathrm{meio} \mathrm{de} \mathrm{interações}$ síncronas e/ou assíncronas, mediadas pelos recursos tecnológicos disponíveis nos ambientes virtuais de aprendizagem (AVA), tais como: fóruns, listas de discussões, webquests, chats, wikis, blogs, e outros. Neste contexto, os materiais didáticos impressos integram-se às tecnologias digitais e às ferramentas dos AVA, propiciando orientações 
de estudos. Como afirma Fernandez (2009, p. 395), mesmo com os avanços tecnológicos, o material didático impresso é um componente significativo da maioria dos programas de $\mathrm{EaD}$, evidenciando-se que não se observa a exclusão de um componente e sua simples substituição por outro.

\section{Desenho metodológico da pesquisa}

O presente estudo configurou-se como uma pesquisa de natureza qualitativa, privilegiando-se percursos metodológicos direcionados à análise de materiais didáticos impressos elaborados para EaD. Richardson (1999, p. 80), entende que: "os estudos que empregam uma metodologia qualitativa podem descrever a complexidade de determinado problema, analisar a interação de certas variáveis, compreender e classificar processos dinâmicos vividos por grupos sociais."

Considerando os percursos metodológicos do presente estudo, inicialmente foi realizada uma pesquisa bibliográfica, com revisão da literatura acerca das reflexões sobre materiais didáticos para $\mathrm{EaD}$ e linguagem dialógica na produção de MDI. Posteriormente, realizamos leituras e fichamentos dos textos teóricos, com vistas a consolidar a revisão da literatura. Por fim, foi aplicado um questionário online com estudantes dos cursos de licenciatura da UFRPE/UAB, no sentido de avaliar a percepção dos licenciandos sobre a linguagem no MDI. O questionário foi disponibilizado na plataforma google drive e organizado em três partes: a primeira priorizou questões sobre perfil dos estudantes; a segunda apresentou questionamentos sobre materiais didáticos impressos; a terceira estava direcionada ao dialogismo (BAKHTIN, 1993) na linguagem utilizada no MDI para a EaD.

$\mathrm{Na}$ próxima seção, iremos apresentar a análise qualitativa das percepções dos estudantes da UFRPE/UAB quanto aos materiais didáticos elaborados para $\mathrm{EaD}$, tendo em vista o que os discentes pensam sobre as características dos materiais e a natureza da linguagem utilizada na produção textual para EaD.

\section{Análise da percepção dos estudantes sobre materiais didáticos}

A pesquisa foi realizada no ano de 2016, com estudantes matriculados em diversos cursos de licenciatura da UFRPE/UAB, tais como: Artes Visuais, Computação, Física, História, Letras, Pedagogia.O questionário foi elaborado na ferramenta Google Drive e aplicado com os licenciandos. A adesão foi maior quando observamos a participação de estudantes do Curso de Licenciatura em Letras, com 65,4\%, seguido de Licenciatura em Pedagogia, com $15,4 \%$. Os alunos estavam matriculados do $3^{\circ}$ ao $5^{\circ}$ períodos de seus 
respectivos cursos e eram oriundos de diversos polos de apoio presencial, localizados em Pernambuco, tais como: Carpina, Pesqueira, Surubim, Recife, Jaboatão e Trindade. Ressaltamos que, por questões éticas, os estudantes não são identificados, recorrendose apenas às letras para nomear as respostas de cada sujeito participante da pesquisa. Inicialmente, questionamos os estudantes sobre como poderiam definir o material didático impresso (MDI) para EaD. Muitos escreveram respostas curtas, como as transcritas a seguir: "um material de apoio essencial no desenvolvimento da disciplina". (Estudante A); "um importante recurso de apoio ao processo ensino-aprendizagem". (Estudante H); "excelente material e facilitador na compreensão dos conteúdos". (Estudante F).

Notamos que os discentes compreendem o MDI como recurso importante para apoiar os processos de ensino e aprendizagem mediados pelas tecnologias na EaD. Indagamos ainda sobre o futuro da mídia impressa. O questionário apresentou, assim, a seguinte pergunta: "Você acredita que o material didático impresso terá seu espaço garantido diante das constantes inovações tecnológicas?". As respostas dividiram-se em dois grandes blocos, ou seja, a maior parte dos estudantes acredita que o MDI continuará tendo papel de destaque, mesmo com os avanços tecnológicos, ao passo que outros argumentaram a escassez futura dos impressos diante das tecnologias digitais. Apresentamos a seguir algumas respostas que defendem a mídia impressa:

"Acredito que, mesmo com as constantes inovações da tecnologia, o material impresso é importante como apoio na aprendizagem do discente, sendo assim, acredito que 0 material impresso não pode ser substituído". (Estudante A).

"Para mim, os livros continuam sendo de extrema importância para a leitura, além de serem fácil manuseio, coisa que não posso fazer com o note para estudar no horário de almoço no trabalho". (Estudante $\mathrm{H}$ ).

"Entendo que há de se oferecerem opções ao aluno uma vez que nem sempre ele estará conectado à internet, portanto, torna-se importante o material físico". (Estudante B).

"É indispensável. Por mais que o computador ajude, tenha tudo o que se quer, o livro é - grande professor, ele é quem nos dá a carga de conhecimento que precisamos"(Estudante L).

As respostas acima transcritas revelam as percepções dos estudantes sobre a mídia impressa, reconhecendo a importância dos materiais didáticos para apoiar os estudos 
na EaD. A facilidade de acesso à mídia impressa, permitindo acesso off-line e facilidades no manuseio para atividades de leitura em qualquer espaço e a qualquer tempo são vantagens apontadas pelos estudantes. Destacamos o depoimento do estudante L que coloca o livro como "o grande professor" no contexto da EaD, pela aproximação com a mediação pedagógica para a construção de conhecimentos.O estudante $M$ aponta a integração das tecnologias e mídias (digitais/impressas) como alternativa importante para o aluno EaD. Na visão do estudante, priorizar apenas um recurso tecnológico pode se tornar algo "restritivo", certamente limitando as potencialidades que a convergência entre diversas mídias e suportes variados pode propiciar.

"Os recursos tecnológicos nunca deverão ser utilizados como única alternativa, deverão, sim, se somar a outros. Todo isolamento, em algum momento, se torna restritivo". (Estudante M).

Outra opinião interessante foi dada pelo estudante C. Este evidenciou a importância da sustentabilidade, tendo em vista a necessidade de considerar a "origem do papel empregado" na produção de MDI, priorizando papel reciclado ou oriundo de práticas de reflorestamento.

"A diferença será feita na escolha da origem do papel empregado, que deve ser de origem reflorestável ou reciclada de boa qualidade. Digitalizar tudo nos deixará reféns da má qualidade da internet." (Estudante C).

Os depoimentos a seguir transcritos atentam para os impactos das inovações tecnológicas na mídia impressa para $\mathrm{EaD}$. O estudante $\mathrm{L}$ compreende o MDI como recurso importante para "um bom aprendizado", em função da praticidade, além de garantir ao leitor a sensação de "tocar a leitura", em virtude do caráter físico do livro. No entanto, o estudante L salienta que os MDI podem ficar escassos, tendo em vista as facilidades para disponibilização de conteúdos na internet.

"O material impresso é de extrema importância para um bom aprendizado, pois além de ser prático (você pode simplesmente abrir o livro em qualquer lugar) ele também nos proporciona a sensação de "tocar" a leitura. Mas infelizmente, com os avanços tecnológicos o material ficará cada vez mais escasso, pois é muito mais simples dispor um conteúdo na internet do que passar pelos processos de impressão". (Estudante L).

$A$ visão do estudante $L$ é similar ao que pensa o estudante $P$. Este defende 0 desenvolvimento das tecnologias no campo da $\mathrm{EaD}$, o que pode provocar a diminuição 
da oferta de MDI para os estudantes matriculados em cursos EaD.

"Embora para mim seja importante ter o material impresso, até mesmo para futuras pesquisas, acredito que a tendência é a diminuição de sua oferta, tendo em vista a modalidade de ensino a distância e o desenvolvimento das tecnologias". (Estudante P).

Outro ponto abordado no questionário priorizou a visão dos estudantes sobre as características de um "bom" material didático para EaD. Inicialmente, buscamos observar a avaliação dos estudantes sobre os MDI utilizados em seus respectivos cursos, no sentido de analisar o que os discentes consideram como MDI de qualidade. Desse modo, questionamos: "Em sua opinião, quais são as características do material didático impresso para EaD? O que um bom material didático para EaD deve conter?" Descrevemos a seguir algumas respostas:

"Ele deve ter conteúdo aprofundado, possibilitando uma formação mais crítica e complexa por parte do aluno. Deve ter um bom design também, ser bem editado e uma apresentação gráfica minimamente atraente. Mas o mais importante é a profundidade em que o autor aborda o conteúdo e o texto que ele apresenta ao seu leitor". (Estudante A).

"Linguagem clara e objetiva. Uma formação adequada à modalidade a que se propõe". (Estudante D)

"Os textos devem possuir leitura agradável, de fácil compreensão e de boa qualidade. 0 aluno $\mathrm{EaD}$ é um agente autoinstrucional e que precisa organizar seu tempo de estudo, necessitando, assim, de um material pedagógico que o auxilie no planejamento de cada disciplina". (Estudante A).

"Os textos devem possuir leitura agradável, de fácil compreensão e bom dinamismo nas atividades, bem como o professor autor dialogar com os alunos através do MDI". (Estudante F).

Notamos que as palavras dos estudantes reforçam aspectos, tais como: recorte aprofundado de conteúdo, design adequado ao MDI, natureza clara e dialógica da linguagem, além de outros importantes componentes essenciais na construção de materiais didáticos que consigam apoiar os estudos na EaD. Quando indagados sobre a linguagem apresentada no MDI, alguns estudantes conseguiram perceber o dialogismo como processo de interação entre o professor/autor e os alunos/leitores, uma característica que certamente pode facilitar a leitura e a compreensão textual, como 
observamos nas respostas:

"Percebo que os autores tentam "conversar" com o leitor/estudante. Em geral o texto é leve e ajuda na compreensão do conteúdo." (Estudante G).

"O material didático possui uma peculiaridade muito positiva, que é o diálogo direto entre leitor e escritor. Quando leio um material didático me vejo num constante diálogo com o leitor, e isso facilita muito a assimilação do tema. Um bom material didático para EaD deve conter imagens, letras maiores, e um diálogo direto com o leitor." (Estudante D).

Também observamos que ainda há aqueles que não estão satisfeitos quanto à linguagem utilizada no MDI. Notamos isto nos depoimentos de alguns estudantes que apontam a linguagem rebuscada e a quantidade de textos como componentes que tornam a leitura cansativa, dificultando a compreensão textual.

"Há um certo diálogo, mas dá muitas voltas, a leitura torna-se cansativa". (Estudante H).

"Há um diálogo com o leitor, porém ainda precisa melhorar." (Estudante I).

"Dialoga sim. Porém, em alguns casos, a linguagem é um tanto rebuscada." (Estudante J).

De modo geral, os alunos realizaram uma avaliação positiva do MDI e o veem como veículo mediador da interação professor/estudantes, tendo a linguagem dialógica uma aliada neste processo. Nesse sentido, destacamos o depoimento a seguir:

"É importante que o autor apresente uma linguagem que dialogue com o leitor. Sabemos que há uma dificuldade por ser um MDI para alunos EaD, e por isso há uma dificuldade. É importante apresentar conteúdos que façam com que os alunos se sintam face a face com o professor. É importante também que o MDI apresente diversos gêneros textuais, incentivando e instigando os alunos no seu processo de aprendizagem." (Estudante K).

O depoimento do estudante $\mathrm{K}$ reforça a necessidade de se produzir o material didático incentivando uma conversa com os estudantes. Conforme Belisário (2003), é importante considerar que o MDI deve "apresentar-se numa linguagem dialógica que, na ausência física do professor, possa garantir um certo tom coloquial, reproduzindo mesmo, em alguns casos, uma conversa entre professor e aluno, tornando sua leitura leve e motivadora". (BELISÁRIO, 2003, p. 140). 


\section{Considerações finais}

A mídia impressa usada em $\mathrm{EaD}$ ainda apresenta-se como instrumento didático importante no processo de mediação pedagógica entre alunos e professores. Segundo Moore e Kearsley (2007, p. 78), "o texto é, sem margem de dúvida, a mídia mais comum empregada na Educação a Distância e, apesar do crescimento da comunicação online que usa texto, a maioria dos textos ainda é veiculada na forma impressa". $\mathrm{Na} \mathrm{EaD}$, os professores precisam conhecer as características dos materiais didáticos impressos, priorizando a natureza dialógica da linguagem (BAKHTIN, 1993) e o caráter "mediacional" (SOUSA, 2001) desses recursos que podem contribuir para a construção de aprendizagens significativas, ancoradas na autonomia dos educandos.

As vozes dos estudantes/leitores destacam a importância da mídia impressa, mesmo diante das inovações das tecnologias digitais no campo da EaD. Na visão dos discentes, os materiais didáticos impressos são aliados no apoio à aprendizagem mediada pelas tecnologias no cenário da EaD. Nesse sentido, comentam sobre a integração e a convergência entre diferentes mídias como fatores relevantes para garantir a oportunidade de estudantes com dificuldades de acesso à internet e aos ambientes virtuais de aprendizagem.

O material didático impresso, amplamente revisitado, debatido, discutido, analisado, agora torna-se alvo de outras abordagens, novas leituras, diante das características da EaD como modalidade educacional que aposta na integração de tecnologias no processo de mediação entre docentes e discentes, valorizando a troca, a relação, a interação, o diálogo como eixos fundamentais na redução das distâncias físicas, promovendo-se uma "educação sem distância" (TORI, 2017), na qual todos aprendem e ensinam, ou seja, "quem ensina aprende ao ensinar e quem aprende ensina ao aprender" (FREIRE, 2002, p. 25).

\section{Referências}

BARZOTTO, V. H. (Org.) Estado de leitura. Campinas: Mercado de Letras, 1999.

BAKHTIN, M. Questões de Literatura e de Estética. São Paulo: Unesp, 1993.

BELO, A. História \& livro e leitura. Belo Horizonte: Autêntica, 2002.

CHARTIER, R. A aventura do livro: do leitor ao navegador. São Paulo : UNESP, 1999. 
FERNANDEZ, C. Os métodos de preparação de material impresso para EAD. In: LITTO, F.; FORMIGA, M. (Orgs). Educação a distância: o estado da arte. São Paulo: Pearson, 2009.

FRANCO, M. Elaboração de material impresso: conceitos e propostas. In: CORREA (Org.). Educação a Distância: orientações metodológicas. Porto Alegre: Artmed, 2007.

FREIRE. P. Pedagogia da autonomia. São Paulo: Paz e Terra, 2002.

LÉVY, P. Cibercultura. São Paulo: Ed. 34., 1999.

LITTO, F. Aprendizagem a distância. São Paulo: Imprensa oficial, 2010.

MOORE, M; KEARSLEY, G. Educação a Distância: uma visão integrada. São Paulo: Thomson, 2007.

PRETI, O. Material didático impresso na EAD: experiências e lições apre(e)ndidas. Anais do III Encontro Nacional de Coordenadores UAB - I Encontro Internacional do Sistema Universidade Aberta do Brasil - Brasília, 23 a 25 de novembro de 2009.

RICHARDSON, R. Pesquisa social: métodos e técnicas. São Paulo: Atlas, 1999.

SNEL. Sindicato Nacional dos Editores de Livros. Painel das vendas de livros no Brasil, resultados 2017/2016, março 2017. Disponível em: Acesso em nov 2017.

TORI, R. Educação sem distância: tecnologias interativas na redução de distâncias em ensino e aprendizagem. São Paulo: Artesanato Educacional, 2017. 